\section{Niñez como objeto del discurso de la prensa durante la dictadura chilena (1973-1989)*}

Childhood as an object of press discourse during the Chilean dictatorship (1973-1989)

\section{Patricia Castillo* \\ Nicolás Peña}

\section{Resumen}

Este trabajo se enmarca en los denominados "nuevos estudios de la infancia". Desde una perspectiva microhistórica se aborda un sujeto hasta ahora relegado de la historiografía tradicional: los niños y niñas. Se busca identificar el imaginario de los niños construido a través de la prensa (Diario La Tercera) durante la Dictadura Militar, distinguiendo los fines con los que los

\footnotetext{
Investigación que se enmarca en el Proyecto Fondecyt Iniciación N ${ }^{\circ} 11140271$ "Niñez en dictadura (1973-1989): Tácticas de resistencia en la niñez identificadas a través de la reconstrucción microhistórica y retrospectiva de los discursos infantiles a partir de tres fuentes distintas".

** Escuela de Psicología, Universidad Academia de Huma-nismo Cristiano. Correo electrónico pcasti-Ilog@docentes.academia.cl
}

conceptos relacionados con la infancia fueron utilizados por el régimen. Se construyó un corpus de textos compuesto por unidades de información publicadas por este medio donde estuviera presente la infancia, desde 1973 a 1989, y se analizaron desde la perspectiva del análisis crítico de discurso (Van Dijk, 2000). Se identificaron seis tópicos que pueden ser propuestos como seis dimensiones para distinguir la infancia. Se observa como dicha categoría cumple diversos roles como tópico de prensa durante estos años, evidenciando las transformaciones subjetivas de un periodo.

Palabras clave: Niñez, Dictadura Militar, Prensa impresa, Historia Contemporánea

\begin{abstract}
This work falls within new studies on childhood from a micro-historical perspective, addressing a subject that has been set aside from traditional historiography: children. It seeks to identify the children's imaginary built through the press (Diario La Tercera) during the military dictatorship, distinguishing the purposes for which the concepts related to childhood were used by the regime. A corpus of news articles (432) was used to analyze emerging discourses on chilhood. Six topics were identified and may be proposed as six dimensions to distinguish childhood. It is noted that childhood fulfills various roles as a topic of press over the dictatorship years, showing the subjective transformations of a period.
\end{abstract}

Key words: Childhood, Military Dictatorship, Printing press, Contemporary history. 


\section{Introducción}

Este artículo busca reconstruir el lugar que ocupó la niñez durante la dictadura chilena (1973-1989) como objeto del discurso en los medios de comunicación que fueron cómplices de la dictadura militar (Monckeberg, 2008). En ese sentido, este trabajo de investigación le asigna a los medios de prensa simpatizantes con el régimen, mediante un análisis del diario La Tercera de la Hora, un rol en la difusión de los mensajes oficiales explícitos e implícitos referidos a diversas temáticas que demarcan las concepciones más generales de infancia y lo normativamente adecuado para relacionarse concretamente con niños y niñas.

Proponemos que la infancia, como construcción social normativa, cumplió diversos roles como tópico de prensa durante los años del Régimen Militar en Chile, y el seguimiento y descripción de estos roles permiten observar, desde una óptica distinta a la tradicional, las transformaciones culturales que demarcaron los ideales de niñez, de familia, de educación, etc.

Para realizar este estudio discursivo nos hemos inscrito dentro de lo que hoy adquiere el nombre de "nuevos estudios sobre infancia"; enfoque proveniente de la sociología de la infancia y del análisis crítico del discurso, desde los cuales se considera a los niños:

Como actores (o agentes) sociales y destacan, tanto su tendencia a reproducir las relaciones sociales dominantes, como también su capacidad de agencia en la modificación del mundo de la infancia y las concepciones sociales que existen al respecto. En tal sentido, los niños se constituyen tempranamente como sujetos plenamente sociales y políticos. (Vergara, Peña, Chavez \& Vergara,

\subsection{Medios de prensa y Dictadura}

La historia de los medios de comunicación durante las dictaduras cívico-militares en Latinoamérica, trátese de los periódicos o de la televisión, puede ubicarse, según propone Borrelli (2010), entre las siguientes tres categorías: la memoria "victimizada", la "heroica" y la de la "complicidad".

En el caso de Chile, la memoria de la complicidad puede rastrearse desde antes de la instalación de la dictadura civico-militar, es decir, la prensa como ejecutora de un papel activo en la amplificación del conflicto que desencadena el Golpe Militar (Bernedo \& Porath, 2003) que puede caracterizarse en una serie de transgresiones que van desde la "utilización partidista de sus contenidos"; "la publicación de información falsa"; "el uso de un lenguaje soez y difamatorio" hasta la publicitación de "la amenaza del uso de la violencia" (p. 124).

En relación, a los acontecimientos que se sucedieron a posteriori del golpe militar, el propio colegio de periodistas ha establecido una versión oficial respecto al papel claramente colaboracionista con el régimen dictatorial de un importante sector de la prensa. Esta colaboración que se tradujo en tergiversar, ocultar y difundir información falsa, la cual dañó irreparablemente no sólo el honor de muchas personas; sino que a su vez, entorpeció las investigaciones que pudieron haber conducido al paradero de los detenidos que aún se encuentran desaparecidos. Desde esa perspectiva el periódico chileno más investigado y sobre el cual existen más denuncias es " $E l$ Mercurio" (Alvear Urrutia, 1987; Dooner, 1989; Dougnac \& Lira, 2009; Sunkel, 1986). 
Ahora bien, ¿qué pasa cuando lo que se intenta investigar excede la dinámica de la violencia explícita de las dictaduras militares, o es más, cuando lo que se intenta reconstruir es el papel funcional de la prensa en la difusión de modelos culturales que no parecen estar tan evidentemente enraizado en la lógica del control del Estado como es el caso de los niños?

Por el grado de implicación de los medios de comunicación, al menos de los más oficialistas, en todo fenómeno cultural moderno, no podemos suponer que habían tópicos completamente ajenos al discurso totalizante de una dictadura, aún con sus fisuras ideológicas. Por tanto, resulta evidente que al indagar sobre la representación de los niños, encontraremos una síntesis de lo que los medios promovían como modelos de identificación. Pero también será interesante observar la manera en que estos ideales propuestos por los medios desde y para los niños prescriben de manera sutil o en ocasiones en forma directa, mociones respecto al deber-ser de los adultos, instituciones y organizaciones.

Es sabido que la retórica sobre la infancia y familia, busca organizar aquello que la sociedad ubicará como la escena del mundo de la seguridad; pero así mismo, las fronteras donde comienza el miedo y la inseguridad, en el caso de la dictadura argentina, por ejemplo, la reorganización de los limites sociales en la dictadura militar prescribe un determinado orden familiar, que puede ser una metáfora del orden social buscado: "el régimen reconocía a los padres de familia la autoridad tradicional, pero a condición de que esa autoridad sirviera para que cada familia se estructurase en arreglo al modelo fijado" (Novaro \& Palermo, 2003: 142). En Chile, la situación fue similar.
En ese sentido, un estudio como este es solidario en objetivo con aquellos estudios que analizan las transformaciones estéticas y culturales tras el golpe de Estado (Errázuriz, 2006, 2009) o bien, los que analizan la conformación de un lenguaje y la instalación y la supresión de categorías que sostienen, inclusive más allá del periodo dictatorial, un escenario discursivo de posiciones maniqueas (Espinoza, 2010; Salermo, 2006). Dichas investigaciones son divergentes en relación al objeto a través del cual esta investigación describe dichas transformaciones, pero sostienen un punto en común en tanto su metodología se construye con la finalidad de hacer emerger de los acontecimientos y significados presentes en la cotidianidad.

\subsection{Infancia en dictadura en la historia y en los medios.}

En Chile, los trabajos más frecuentes sobre el tema se relacionan con hitos específicos (Ley de Responsabilidad Penal Adolescente [Ley RPA]) o con sujetos específicos (niños pobres, niños delincuentes) (Molina, 2009; Condeza, 2005; Sepúlveda Prado, 2014). Y todos se ubican en la posdictadura, como consecuencia especifica de los compromisos estatales contraídos con las organizaciones internacionales tras la ratificación por parte del gobierno chileno de la convención de los derechos del niño (1990).

Los estudios sobre infancia y niñez en dictadura, son fundamentalmente de carácter histórico. El más detallado respecto al periodo es el de Jorge Rojas (2010), quien hace una revisión de la infancia a lo largo de todo el Chile republicano a partir de numerosas fuentes institucionales, estudios académicos y otras referencias, siendo uno de los estudios más acabados al respecto. 
En el capítulo en que Rojas (2010) aborda el periodo de la dictadura, se pueden distinguir al menos 5 dimensiones de la experiencia infantil en la época:

- Como víctimas directas de la represión de parte del Estado.

- Como objeto de disputa ideológica a través de las prácticas educativas, la ritualidad militar y patriótica.

- Como objeto de instituciones de seguridad nacional.

- Como objetos de la filantropía.

- Como motor de la resistencia.

Estas coordenadas nos han permitido construir un panorama general en el que se inscribe el uso de la figura de los niños y las niñas en los medios de comunicación, particularmente el escrito.

Sobre otro periodo histórico, encontramos el estudio de Claudio Duarte \& Littin Menz (2002), que realiza un seguimiento del uso de la imagen de los niños en los medios de la prensa escrita, situado en la posdictadura, a partir de la identificación de los discursos que elaboran estos medios, considerándolos como productores de realidades sobre infancia y juventud. El estudio se presenta como un aporte para comprender cómo las imágenes que se elaboran sobre los sujetos niños, niñas y jóvenes desde los medios de comunicación tienen una alta incidencia en los modos en que la sociedad se relaciona con estos grupos sociales.

En este sentido, el estudio distingue 4 tópicos que concentran el abanico de imágenes con las que la prensa presenta a la infancia, sean estos:

Niños, niñas y jóvenes en preparación para el futuro: todas las noticias cuya intención explícita o implícita sea "la definición y el reforzamiento de los roles que les correspondería jugar en nuestra sociedad a los mayores (adultos y adultas) respecto de los menores (niños, niñas y jóvenes)" (p. 49).
- Niños, niñas y jóvenes como problema social: imágenes en donde los problemas sociales con los que se relaciona el sujeto se observan con una mirada negativa en la medida en que se refieren a jóvenes. (p. 65).

- Niños, niñas y jóvenes como pretexto de lo institucional: se referiría al uso que reiteradamente los medios dan a su imagen en notas cuya finalidad es hacer aparecer "otras temáticas, especialmente referidas a lo institucional” (p. 83).

- Niños, niñas y jóvenes como actores... consumidores y ciudadanos: correspondería a una forma de construcción realizada por los medios, que implementa un mecanismo de revisibilización y que es un segundo momento del mecanismo de invisibilización que se observa en los puntos anteriores (p. 99).

\section{Metodología}

\subsection{Corpus}

El corpus fue construido a partir de una revisión de archivo correspondiente al diario La Tercera. La selección de este medio responde a la necesidad de tener una representación de los discursos oficiales del proceso matizados por un medio de comunicación simpatizante con el régimen. Si bien se declaraba independiente, el duopolio que estableció con El Mercurio, con el apoyo explícito del régimen (Monckeberg, 2008), le permitió concentrar el discurso oficial que venía desde las autoridades, canalizándolas a la población a lo largo de todo Chile. La representatividad de este discurso y el impacto que tenía el medio en todo el territorio, permiten evidenciar las formas en que el régimen se relacionaba con la infancia.

Por lo amplio del proceso abarcado, que prácticamente considera dos décadas, se hizo necesario delimitar los años y meses de estudio bajo criterios específicos que intentan focalizar las instancias donde la prensa potencialmente podría hablar sobre la niñez, considerando también los años donde se evidencian las 
mayores transformaciones del período. Los años seleccionados y los motivos se expresan en la siguiente tabla:

Tabla 1. Selección de años para elaboración de corpus.

\begin{tabular}{|c|l|}
\hline Año & \multicolumn{1}{|c|}{ Motivo de selección de año } \\
\hline 1973 & Año del golpe de Estado. \\
\hline 1975 & $\begin{array}{l}\text { Incidencia de la crisis económica e insta- } \\
\text { lación de primeras transformaciones en el } \\
\text { modelo. }\end{array}$ \\
\hline 1979 & $\begin{array}{l}\text { Año Internacional del Niño declarado por } \\
\text { la ONU. Segundo año de la Teletón. }\end{array}$ \\
\hline 1983 & $\begin{array}{l}\text { Año donde estallan las protestas sociales } \\
\text { contra el régimen. }\end{array}$ \\
\hline 1985 & $\begin{array}{l}\text { Punto de inflexión en las movilizaciones y } \\
\text { crisis económica. }\end{array}$ \\
\hline 1988 & $\begin{array}{l}\text { Cierre del período tras el plebiscito que re- } \\
\text { solvió el fin de la dictadura. }\end{array}$ \\
\hline
\end{tabular}

Dentro de los años señalados, se consideró marzo por ser el fin de las vacaciones $y$ comienzos del año escolar, y diciembre, por el fin del año escolar y la celebración de la Navidad. Esta selección busca dar cuenta de todo el período, partiendo desde un enfoque que analiza los procesos, más allá de la selección a partir de años y meses "hito". Aunque los productos informativos seleccionados no se abordaron desde una perspectiva cuantitativa, cabe destacar que la revisión está compuesta por un corpus de más de 300 días de noticias durante 16 años.
Se revisaron los meses completos de marzo y diciembre en los años señalados, haciendo una primera revisión de la edición diaria donde se reconocieron todos los productos comunicativos (noticias, editoriales, publicidad, insertos, etc.) donde estuviera presente la infancia en cualquiera de sus representaciones, en las distintas secciones que componen el periódico. En este período, se reconocieron 432 productos que hacían referencia directa a la infancia, las cuales fueron revisados en su conjunto.

\subsection{Análisis}

El análisis se inicia desde una premisa hermenéuticaque busca interpretar los discursos elaborados en los medios de comunicación oficiales, desentrañando los conceptos y los enfoques que estos medios construyen sobre la infancia.

Los textos se abordan a partir de un análisis crítico del discurso (ACD) que entiende el lenguaje como una práctica social en un contexto determinado, buscando dar cuenta de las relaciones entre el lenguaje, el poder, la historia y la ideología. "Los discursos ejercen el poder porque transportan un saber con el que se nutre la conciencia colectiva e individual" (Jagger, 2003: 69).

Se aplica una adaptación de la perspectiva de ACD desde el paradigma inaugurado por Teun Van Dijk (2000), quien se propuso desarrollar una propuesta teórica y metodológica que permitiera desentrañar los discursos hegemónicos desde una posición crítica e interpretativa que evidenciara las relaciones de poder detrás de los productos informativos. Su propuesta se basa en una 
aproximación al concepto de discurso a partir de tres dimensiones principales:

“a) el uso del lenguaje; b) la comunicación de creencias y c) la interacción en situaciones de índole social [...] Una tarea característica del estudio del discurso consiste en proporcionar descripciones integradas en sus tres dimensiones: ¿cómo influye el uso del lenguaje en las creencias y en la interacción, o viceversa?" (Van Dijtk, 2000, 23).

Se hizo una primera revisión de la prensa reconociendo los productos comunicativos que dieran cuenta del contexto político, económico y social en cada año. De esta forma, se revisaron los productos que hacían referencia a la situación económica (crisis, pobreza, análisis económico) y a la situación política (resistencia, partidos políticos y movilizaciones sociales). Teniendo este conjunto, se tomaron todos aquellos que hicieran referencia a la infancia, considerando los cruces con otros tópicos revisados. En consideración a la variedad de las referencias que hace la prensa sobre este tema, primero se aborda al texto a partir de su intención comunicativa, donde pueden existir mensajes cuyo destinatario sea el público infantil, mensajes destinados a adultos y niños con contenidos infantiles o mensajes destinados directamente a adultos con contenidos sobre niños.

El tipo de productos que se revisaron fueron de distinto tipo, intentando abarcar la totalidad de los que presentaba el medio impreso. De esta forma, se tomaron noticias, reportajes, entrevistas, fotografías, avisos publicitarios, columnas de opinión, entre otros. Considerando su variada naturaleza, donde se pueden reconocer discursos informativos, discursos de opinión y discursos publicitarios, para fines del análisis se optó por tomar principalmente los discursos informativos, ya que, al referirse a la infancia, entregaban más información. De todas formas, se tomaron elementos de los otros discursos, de opinión y publicitario, cuando se consideró pertinente para reforzar algunas ideas del análisis.

En las comunicaciones que hacen referencia directa a la infancia, se aplicó una categorización que busca dialogar con las investigaciones que han abordado a la prensa y los discursos sobre infancia y que ya han sido mencionados en este trabajo. Las dimensiones consideradas se enmarcan en seis grupos:

1. El niño como problema social.

2. Legitimación de militares y gobernantes a partir de los niños.

3. Pauta de comportamiento a la ciudadanía y la familia.

4. Legitimación del saber experto sobre los niños.

5. El niño consumidor.

6. El niño como víctima de los que se oponen al régimen.

Los productos comunicativos referidos a la infancia que se identificaron en la primera selección fueron agrupados en estas seis dimensiones. Posteriormente, se seleccionaron aquellos productos más representativos de la idea que engloba la dimensión, tratando de abarcar, en esta segunda selección, las dos décadas del período considerado.

El orden que ofrece la categorización de los textos permite aplicar a cada producto una matriz de análisis que considera los puntos sugeridos por Van Dijk (2000) a partir del ACD, donde reconoce dos planos que se extraen del producto analizado, un primer plano significado/ texto y un segundo plano formal/texto-contexto. El primero se enfoca en las macroestructuras semánticas, los significados globales que se ubican en el nivel temático, que luego pasa al nivel de los significados locales donde los significados de carácter explícito se encuentran con aquellos de tipo implícito o indirecto 
(implicaciones, ambigüedades, omisiones, polarizaciones y prejuicios). El segundo nivel de análisis, se enfoca en los aspectos formales reflejados en las estructuras formales "sutiles", como los marcadores lingüísticos (orden de las palabras, coherencia, estilo, actos del habla, etc.) y la construcción de realidades. Finalmente, en el nivel contextual, se revisa el texto en relación a las representaciones mentales de la memoria que descansan en cuestiones históricas, políticas, sociales y económicas.

Tabla 3. Propuesta para análisis crítico de discurso.

\begin{tabular}{|l|}
\hline Plano Significado/texto \\
\hline Nivel temático: significados globales \\
Nivel de significados locales: \\
-De carácter implícito o indirecto \\
-De carácter explícito o directo
\end{tabular}

(Browne et al., 2010: 30)

\section{Resultados}

Un diario de circulación nacional, como La Tercera, debió abordar los conflictos y las tensiones que se dieron en el periodo, ciñéndose a una línea editorial 'objetiva e independiente' que, sin embargo se encargaba de transmitir y reproducir los mensajes oficiales de las autoridades y las instituciones encargadas de dirigir el gobierno y la economía. "El control de la situación política", "Las estrategias para salir de la crisis" y "La asistencia a la pobreza", son titulares recurrentes durante todo el periodo, donde se mezclaban con noticias relacionadas al deporte, a la crónica roja o a la emergente farándula televisiva. Dentro de todo esto, existió un espacio para tratar temas referentes a la niñez que, analizándolas en su conjunto, se inscriben en determinados tópicos que no dejan de aparecer durante toda la dictadura.

El trato que le dio la prensa a la niñez se cruza con otros tópicos abordados en ese periodo (política, economía y situación social), aunque presenta una propia forma de abordarla a partir de grandes temas donde cada producto comunicativo se puede inscribir:

- La presentación del niño como problema social y la asistencia del Estado y las instituciones.

- Legitimación de militares y gobernantes a partir de los niños, usándolos para mostrar el lado humano y cercano de las autoridades.

- Pautas de comportamiento a la ciudadanía, presentando ejemplos del ciudadano ejemplar y la importancia de la familia en el cuidado del niño.

- El saber experto, cómo principal voz legitima respecto a las pautas de crianza y normalidad en niños y niñas.

- El niño como consumidor y su participación en la economía de mercado.

- Ya hacia fines de los '80, un nuevo tópico aparece cuando se trata de condenar las acciones de resistencia a la dictadura, presentando a los niños (y a los pobres) como víctimas de los extremistas y violentistas.

Todos estos tópicos aparecerán en distintas formas durante todo el periodo, posicionando al niño en un espacio determinado por su relación con las instituciones que lo bordean, con la economía y con la tensión política y social que se vivía. 


\subsection{El niño como problema social}

Desde los primeros años de dictadura, la mayoría de las noticias presentan la imagen de una infancia expuesta que debe ser protegida. Es el niño pobre y/o abandonado el que requiere de atención y cuidado ("se cumplió meta del millón de juguetes, pero aún faltan", 18 dic., 1973; "emotivo paseo a los huerfanitos de Rancagua", 1 dic., 1975) y son las instituciones las encargadas de este trabajo. La pobreza en el niño es objeto de reflexión, cosa que no sucede con la pobreza en general ("zapatitos rotos", 25 dic., 1975) y es el foco de trabajo de las fundaciones dedicadas a la infancia (" Ayude a salvarlos!", 28 dic., 1975, Fundación Niño y Patria, fundada por Carabineros en 1963). Esta ayuda se enfoca en campañas de saneamiento o higienización de la infancia expuesta, que busca alejarlos de la "mala vida" "exitosa es la campaña para erradicar vagancia infantil", 9 mar., 1979). También se da espacio a los estudios en torno al tema ("simposio sobre la pobreza en la niñez"; "Pobreza impide el desarrollo de 70 millones de niños", 6 dic., 1979). La caridad hacia el niño alcanza su máximo punto comunicacional con el inicio de la Teletón en 1978, bajo los conceptos de unidad nacional y visión de futuro. Desde los llamados a colaborar y a unirse a "la cruzada" hasta la superación de la meta y los primeros resultados concretos, la Teletón se instala como hito característico de la relación de los privados para con los desvalidos ("Es una noble cruzada a favor de los niños", 1 dic., 1979).

Ya en la década de los '80, la presencia del niño se intensifica en la crónica roja, siempre ligada a condiciones de pobreza y marginalidad ("hasta menores de 4 años detectados inhalando el maldito neoprén", 11 dic., 1983; "delincuencia atrapa a nuestra juventud. Niños y jóvenes no trepidan en matar o robar", 2 dic., 1985). La presentación del niño indefenso se soslaya gracias a la intervención directa de las instituciones, principalmente las ligadas al Estado, presentando los éxitos de las medidas de protección a la infancia ("este Gobierno velará siempre por los niños de Chile", 3 dic., 1983; "desnutrición infantil se bate en retirada", 10 dic, 1983).

Este tópico se ve reflejado en distintas instancias a lo largo de todo el periodo; aunque siempre presentando un enfoque similar, como en esta noticia de 1979:

\section{Ejemplo 1.}

La Tercera de La Hora, 13 de marzo de 1979 OPERATIVO PARA ERRADICAR LA VAGANCIA Y MENDICIDAD INFANTIL

El rostro está pálido, resaltan las grandes ojeras y la mirada aparece vaga. Está descalzo y sus pies hace mucho tiempo que no usan zapatos. La vestimenta es andrajosa y la cabeIlera abundante y desordenada en manifiesto estado de desaseo. El niño tiene apenas 10 años y su desnutrición es evidente.

(...) Por lo general son niños que han perdido la noción de hogar. No hay respeto porque el padre sale a beber y la madre que va perdiendo la visión familiar se conforma con que los chiquillos salgan de la casa. Así no habrá preocupaciones de darles de comer y atenderles las necesidades. El padre está cesante y su impotencia tiene como puerta de escape el alcoholismo" (p.8). 
Esta noticia cuenta la experiencia de Carabineros en el despliegue del operativo para erradicar la vagancia y mendicidad infantil en Concepción. Explícitamente, se puede ver una descripción de una realidad social determinada que afecta a los niños hijos de los pobres que por razones de negligencia parental son arrojados a la calle donde adquieren malos hábitos y están sometidos a numerosos riesgos físicos y morales. Se describe una caracterización cuantitativa en una región determinada, localizada a nivel regional (la ciudad de Concepción), sin datos nacionales. Implícitamente, se visibilizan causas estructurales como la cesantía, pero se responsabiliza a los adultos padres y madres desde un juicio moral, distinguiendo prácticas de negligencia como el alcoholismo, explotación laboral y la debilidad femenina.

El Estado se presenta como el encargado de resguardar a los niños y, a través de Carabineros, restituye las condiciones para la rehabilitación y el respeto de sus derechos. El diagnóstico que se hace es que la familia no protege, entonces se debe reemplazar la función paterna. La intervención del Estado no incorpora a padres o familia en la rehabilitación de los niños, sólo son suplantados. La visión de la infancia se criminaliza en el contexto de pobreza en la que viven los niños, donde la protección a esta se encuentra en la institución de Carabineros y en la intervención del Estado.

\subsection{Legitimación de militares y gobernantes a partir de los niños.}

Desde el comienzo de la dictadura, la prensa busca establecer una relación entre las máximas autoridades del régimen y los niños ("siete niños fueron reyes en la Nochebuena en hogar del General Leigh", 26 dic., 1975; "Primera
Dama distribuyó ajuares a recién nacidos", 26 dic., 1975). Se intenta presentar un clima de normalidad donde los niños tienen un espacio, evidenciando el proceso que se vive; pero a partir de cómo la autoridad se preocupa de mantener el orden y la calma, siempre en comunicación con la población, como en la noticia "una carta impostergable" (21 dic., 1973) donde una niña le escribe a la Junta de Gobierno para que le den el bono de navidad a su padre obrero.

El año '79 fue especialmente importante, ya que la ONU declaró el Año Internacional del Niño y la prensa ocupó varias páginas en cubrir todos los eventos que ocurrían en relación a este año. No se quedan afuera de la celebración las personalidades internacionales ("Pelé adhiere al Año Internacional del Niño", 12 mar., 1979), la televisión ("con grandes novedades la TV se suma al Año Internacional del Niño", 30 mar., 1979) y la Primera Dama, que desde los años anteriores ya venía siendo la cara visible de la relación del gobierno con la infancia ("Primera Dama inaugura el Año Internacional del Niño", 14 mar., 1979; "debemos dedicar una década a todos los niños chilenos. Primera Dama en Valparaíso", 29 dic., 1979).

En la década de los '80, se continúa en esta línea, donde Lucia Hiriart sigue siendo la voz autorizada para comunicarse con los niños, con un discurso que viene del cristianismo y que apunta a superar las diferencias para preocuparse por los niños ("Mensaje de la Primera Dama a los niños", 25 dic., 1983).

A pocos meses del Golpe, se refleja en esta directa relación entre los niños y las máximas autoridades de la Junta de Gobierno. 


\section{Ejemplo 2.}

La Tercera de La Hora, 8 de diciembre de 1973 Lo anunció general Pinochet

\section{VIEJO PASCUERO TENDRÁ SALVOCON- DUCTO EL 24}

¡El Viejo Pascuero tendrá salvocoducto para repartir juguetes en Nochebuena! La noticia se conoció gracias a un emotivo intercambio de cartas entre tres niños y el Presidente de la Junta de Gobierno, general Augusto Pinochet. Así se despeja la incógnita de muchos pequeños de Chile respecto a la próxima Navidad, ya que se ignoraba cómo se las arreglaría el Viejo Pascual para cumplir su labor a raíz del toque de queda.

(...) "Señor Pinochett (sic): Yo quiero que Ud. por favor tome presos a todos los upelientos y haga el bien a Chile, nuestra querida patria con el señor Lee, con el señor Merino, con el señor Mendoza y Ud. con los cuatro militares de la Junta Militar de Gobierno. Por favor, le quiero preguntar a Ud. si va a haber toque de queda el día de Navidad. (...) Señor Pinochet se lo pido por Nochebuena y Navidad. O si no, que los militares lo dejen pasar" (...)

(...) "Augusto Pinochet Ugarte (...) saluda muy atentamente a los niños (...) y les señala que ha recibido la carta en que Uds. saludan a la Junta de Gobierno y les agradece su fervor patriótico y sus buenos deseos. Adjunto encontrarán una copia del salvoconducto que se entregó al Viejo Pascuero para que pueda repartir los juguetes. Los soldados también tienen niñitos como ustedes y estarán en las calles, cuidando la tranquilidad de los hogares, para que tengan una Pascua más feliz que en los años anteriores. Reciban Uds. y sus padres mis afectuosos saludos" (p.4).
Esta noticia presenta un intercambio de cartas entre unos niños y Pinochet, y apela a mostrar un clima de normalidad en un estado de excepción y toque de queda.

La carta porta una pregunta que evidencia el contexto militarizado que vivía Chile. Los niños comprenden el funcionamiento de la institucionalidad, la situación que se vive y las normas que están impuestas, incluso ocupan un lenguaje peyorativo ("los upelientos") y comprenden y honran la misión que realiza la Junta.

La respuesta de Pinochet busca entregar un mensaje: el sentido patrio pasa por adherir y apoyar las medidas de la Junta. Con ello, a su vez incluye en su imagen de militar un rasgo de cercanía con los niños, entregándoles una solución, sin vulnerar la realidad para apoyar la fantasía.

En la respuesta de Pinochet se entrega una imagen de los soldados, involucrados en la ejecución de las medidas del estado de sitio, desde un lugar de semejante (tienen hijos, quieren el orden, buscan una buena navidad). Con esta comunicación se los humaniza y se les destaca por su sacrificio por la patria.

Enestanoticia, hay un intercambioepistolardonde se transcriben las cartas sin interpretaciones ni correcciones ortográficas, dejando algunas palabras equívocas de los niños para que puedan ser escuchadas de manera directa y respondida bajo el mismo estatuto.

\subsection{Pauta de comportamiento a la ciudadanía.}

A través de la prensa, las autoridades transmiten sus mensajes, muchas veces en forma 
de orden a la ciudadanía, estableciendo claramente las pautas de comportamiento que debe seguir la población, interviniendo directamente los espacios donde están presentes los niños, como la escuela. Esta tendencia se matizará con los años, aunque siempre encontrará un espacio para transmitir las ideas dominantes del régimen.

\section{Ejemplo 3.}

La Tercera de La Hora, 19 de diciembre de 1973

Secretario técnico del Ministerio de Educación

“LA EDUCACIÓN NO SERÁ UN INSTRUMENTO DE CONCIENTIZACIÓN POLÍTICA"

Quedarán marginados del proceso educacional quienes pretendan utilizar la educación como un instrumento de concientización política, sea cual fuere la doctrina o ideología", dijo ayer el secretario técnico del Ministerio de Educación, Luis Velasco. Velasco destacó que la educación será profundamente humanista, de fondo cristiano, "donde el hombre sea el centro y el objeto" frente al cual el Estado deberá ejecutar sus instrumentos y organismos.

(...) "Si hemos dado una batalla - añadió Velasco - en contra de los predicadores del odio, lo único moralmente lícito que podemos hacer es todo lo contrario y actuar con amor frente a los demás" (p. 18).
Esta noticia hace referencia a la prohibición y censura de textos escolares, estableciendo las medidas específicas del Ministerio de Educación (retiro de libros, edición de textos) transmitidas a partir de un comunicado oficial.

Explícitamente, se señala que la educación previa al golpe, es ideológica y por ello es una educación para el odio. Se propone una educación "para el amor", enfocada en una educación humanista y cristiana. La influencia marxista e ideológica se ubica en áreas específicas del conocimiento: castellano, ciencias sociales y filosofía. A los padres se los considera como en riesgo de contaminación ideológica y por ello, deben ser supervisados en el tipo de lecturas que ofrecen a sus hijos.

Se trata de un tipo de comunicado que va dirigido a las direcciones de los colegios y liceos de Chile. Implícitamente, hay una polarización unidimensional en la discusión respecto a los contenidos: no alude a la competencia, ni a estándares de rendimiento, sólo apela a la desideologización presente en los contenidos: borrar la concientización político-marxista.

El texto denota el uso de términos imperativos, como "los apoderados deberán", dando cuenta de un proceso unidireccional y no dialógico. La localización de las nuevas normas en la educación está puesta en la Junta de Gobierno. El comunicado entrega procedimientos a seguir que no están sometidos a discusión, ya que vienen dados desde la voz "oficial". 


\section{Ejemplo 4.}

La Tercera de La Hora, 25 de diciembre de 1983

\section{MENSAJE DE LA PRIMERA DAMA A LOS NIÑOS}

Queridos niños:

Hace ya diez años que estamos juntos y he podido dirigirme a ustedes en Navidad. Han sido diez años, y al comienzo de la década muchos de ustedes eran pequeñitos: hoy día son mayorcitos, y algunos son adolescentes, pero siempre están cerca de mi corazón, de mis sentimientos.

(...) Esto es lo que le pide una mujer que se siente la abuelita de muchos niños, que son los niños chilenos. Mis hermosos y encantadores niños, que hacen olvidar las penas, suavizan el camino del trabajo y nos dan la ilusión de que vamos a tener cada día hombres y mujeres para nuestra patria (p.10).

El análisis de este tipo de comunicaciones a la población permite visualizar la diversidad de sentidos con los que la imagen de la niñez se utiliza en los discursos adultos, discursos que en su mayoría están dirigidos a otros adultos, aunque dichos receptores son también ubicados en una posición infantil, es decir, se les prescriben y proscriben formas de sentir y comportarse. Un ejemplo claro de esta forma enunciativa del poder dictatorial y del concepto que porta respecto a la población a la que se dirige es el discurso emitido por Lucia Hiriart, quien se erige desde el lugar de abuela de los niños y por ello de madre de los chilenos adultos que componen la sociedad. Desde dicho estatuto y en su condición de madre y abuela, la esposa del dictador se presenta encarnando un ideal de bondad, rigor y experiencia en la vida ante la cual sería irrespetuoso cualquier acto de rebeldía y desacato.

\subsection{Legitimación del saber experto.}

Durante todo el período, las noticias re cionadas a las pautas de crianza son dirigidas hacia las mujeres, buscando orientarlas en la toma de decisiones a partir de un saber experto ("no mate al viejito pascuero", 11 dic., 1973, "la mala digestión hace llorar al niño", 3 dic., 1975). Con una menor presencia en los primeros años, hacia fines de la década del ' 70 , este tipo de noticias se diversifica en temas y contenidos, presentando también ejemplos del "niño ideal" "niños-soldados se lucen en dura campaña militar", 4 mar., 1979 ; "el ABC de un buen alumno", 7 mar., 1979), tendencia que se prolongará durante la década del '80, presentando estudios especializados sobre temas familiares y escolares " ¿Cómo calmar los miedos nocturnos en el niño?", 8 mar., 1985; "Suplemento Orientador Educacional: Cuando el niño es prioridad", 21 mar., 1988).

La legitimación del saber experto a través de la presentación de las noticias muchas veces entregaba ideas que, de no ser respaldadas por este "saber", carecerían de todo sentido, como la que se presenta a continuación. 
Ejemplo 5.

La Tercera de La Hora, Sección de Mujer a Mujer. 10 de diciembre de 1975

Opina pediatra francés:

\section{"LOS NIÑOS SON MÁS INTELIGENTES SI NACEN EN UNA PIEZA OSCURA"}

SAN FRANCISCO, Diciembre (UPI).- Los niños son más inteligentes, más saludables y mejor adaptados si nacen en una habitación en penumbra y si se les dan suaves masajes, según el especialista en obstreticia francés Frederick Leboyer.

(...) Leboyer manifestó que en los últimos 1.000 de los 10.000 alumbramientos en que ha estado presente ha usado sus métodos de nacimiento buenos gentiles para hacer el ingreso del infante tan suave, tan placentero y tan lleno de cariño como es posible (p. 35).

Esta noticia, sacada de un medio internacional, intenta dar cuenta de la incidencia de la investigación médica sobre las prácticas de cuidado. Incluye elementos observables con el objetivo de disciplinar la maternidad, validando el saber experto y extranjero a partir de datos empíricos.

La noticia se ubica en la Sección De Mujer a Mujer, evidenciando un sesgo de género en noticias relacionadas a la infancia, aunque sea un mensaje dirigido a los profesionales de la medicina.

\subsection{El niño como consumidor}

El mercado de la navidad tiene presencia desde 1973 a través de la publicidad que se enfoca en la promoción de juguetes. Algunas ocupan la idea de "reconstrucción nacional" para su posicionamiento, como la Industria Nacional de Plásticos-Plasinac que señala en su aviso: "reconstruir la felicidad de los niños es reconstruir Chile" (8 dic., 1973). Hacia fines de la década, el consumo se diversifica en ropa, deportes y entretención ("artículos deportivos reemplazaron esta pascua a los juguetes bélicos", 27 dic., 1979), incluso dando espacios para que los niños opinen y elijan ("Ios juguetes: opiniones y esperanzas de los niños", 13 dic., 1979). Durante toda la década, la infancia se aísla de la situación que se vive, y se incluye en otros temas como la caridad o el consumo en Navidad, presentando un estado de normalidad y unidad nacional. De a poco, el niño es definido como sujeto de consumo, primero respondiendo a la contingencia de la navidad y luego diversificando sus intereses, apareciendo no sólo son juguetes, sino también entretención o moda ("Circo: espectáculo para los niños, pero que lo disfrutan más los padres", 5 mar., 1983; niños piden desde muñecas hasta cohetes nucleares al viejo pascuero", 15 dic., 1985).

Esto se refleja también en la televisión, donde se construye un espacio especialmente dirigido para este público: 


\section{Ejemplo 6.}

\section{La Tercera de La Hora, 31 de marzo de 1979 GRANDES NOVEDADES OFRECERÁ LA TV CHILENA EN EL AÑO DEL NIÑO}

Cuatro programas de producción nacional Sacacorcho y Sacapunta, Canal 13; Los Bochincheros, Canal 9, y la Cafetera Voladora, Canal 7, junto a otros tres envasados: "infantilísimo", Canal 9, "Fábrica de Sonrisas" y "La Gran Esfera Azul", Canal 13 - tendrán en 1979 la misión de conmemorar el Año Internacional del Niño. La Televisión, como medio de comunicación con objetivos concretos de informar, entretener y entregar cultura, no podía - según explicaron los ejecutivos de los tres canales - quedar al margen de esta importante celebración.

(...) La Tercera conversó con sus creadores y responsables. Conoció los equipos de trabajo que tendrán la difícil misión de hacer sonreír y aportar al desarrollo del mundo infantil. (...) No estarán tampoco ausentes las campañas para contribuir a la erradicación de la vagancia infantil y otros problemas sociales que atañen al niño (Revista Cine, Radio, Televisión, p. 2).

Se explicita el compromiso de la TV con los objetivos que, a nivel de Estado, se han establecido para la infancia. La televisión se pliega a estos objetivos para desarrollar ciertas políticas comunes. Implícitamente, se establece que los niños pueden competir en la selección de los programas, posicionándose en un lugar de consumo donde pueden discriminar cuando es un buen programa y lo que tiene que contener: ser entretenido, con chascarros y risas por los infortunios del adulto. Se utiliza la burla al mundo adulto como recurso de entretención. Hay otros personajes que incluyen contenidos dispuestos por el Ministerio de Educación, como estimular su curiosidad científica. Se puede deducir una pedagogización moral: ser conscientes de las buenas intenciones, de los problemas del pobre, buscando realizar acciones prácticas, más allá de los programas. Los niños cumplen un rol tal como los adultos: elegir lo que quieren ver.

\subsection{El niño como víctima de los que se oponen al régimen}

Durante la década del ' 70 , no se establece una relación entre los niños y los casos de violaciones a los derechos humanos o las acciones de resistencia. Será recién en 1979 cuando la prensa oficial por primera vez vincula directamente a la infancia con algún caso de este tipo ("piden que declare plana mayor de Investigaciones en Caso Anfruns", 13 dic. 1979).

Esto seguirá igual hasta la primera mitad de la década de los '80, momento donde el niño ocupa un espacio en el imaginario del Chile "oficial" representado en la prensa que apela a reflejar la pureza de la infancia, por lo que resulta ser un buen elemento cuando se habla de "unidad nacional" y "búsqueda de la paz", donde incluso los mismos niños son los encargados de dar la pauta de comportamiento a la sociedad ("Mensaje de los niños en navidad: los hombres deben vivir en paz y hacer buenas acciones", 25 dic., 1985). Esto se intensifica en los últimos años de dictadura, donde los niños aparecen en algunas noticias que refieren a hechos de protesta, resistencia y movilización nacional, siempre como víctimas. En titulares que ocupan portadas que son reforzadas con fotografías, los niños parecen ser las víctimas circunstanciales 
de las acciones "extremistas" realizadas por "terroristas" ("bomba voló mano a niño", 10 mar., 1988; "niño víctima de bomba podría perder sus ojos", 11 mar. 1988; "32 niñas había en la comisaría ametrallada", 12 mar., 1988).

La siguiente noticia refleja este trato de la prensa cuando se incluyen niños en hechos de protesta o resistencia:

\section{Ejemplo 7.}

La Tercera de La Hora, 10 de diciembre de 1988

Trasladado de urgencia a (sic.) Hospital Roberto del Río de Santiago

\section{ENTRE LA VIDA Y LA MUERTE SE DEBATE NIÑO HERIDO EN COPIAPÓ}

El menor llegó a las 17:00 horas del citado hospital proveniente desde Copiapó, ciudad donde por la mañana le fue amputado el brazo izquierdo a la altura del antebrazo, y la casi totalidad de la mano derecha, después que una bomba le volara la extremidad. El hecho ocurrió en el sector céntrico de la ciudad cuando el pequeño tomó una caja que contenía explosivos y que le explosión en sus mano.

(...) El padre: "Estaba trabajando en el taxi cuando me enteré de la noticia sobre un niño herido por una explosión, fui a mi casa y no estaba el niño, me fui a la casa de mi madre y tampoco estaba, de allí fui al colegio y al hospital, todo es tan terrible, aquí entré corriendo, vi a mi señora y supe que era mi cabro el herido" nos señaló visiblemente quebrado el padre (p. 4).
En esta noticia se describe un accidente en el que un niño fue víctima casual de los atentados con explosivos perpetuado por sujetos que se localizan en la resistencia. Explícitamente, se responsabiliza a la izquierda del accidente, identificando a las organizaciones con nombre exacto: Partido Comunista de Chile (PC), Frente Patriótico Manuel Rodríguez (FPMR) y el Movimiento de Izquierda Revolucionaria (MIR). Se resaltan las secuelas físicas y psicológicas que causaron el accidente en los niños, destacando el dolory la consternación de padres y vecinos. Aunque no se anuncia, se sugiere que corresponde a gente pobre, buscando desasociar a las organizaciones políticas de los supuestos intereses de los pobres.

Ocupando a los niños como los más expuestos y vulnerables, hablan todas las instituciones que bordean a los niños (iglesia, colegios, padres). Se refuerzan conceptos como "progreso, libertad y justicia", "atentar a", generalizando ideas a toda la nación: "demandas de paz y justicia que claman los hombres de nuestro pueblo".

Resulta interesante ver las noticias que acompañan a este titular. En un pequeño recuadro, se lee: "rechazo a recurso a extremista", presentando la idea de que la justicia está funcionando al condenar este tipo de actos. El contexto de la noticia es la proximidad de las elecciones tras el plebiscito, por lo que se busca desacreditar a las organizaciones de izquierda ante sus supuestos y/o potenciales votantes.

\section{Conclusiones}

Al revisar los distintos productos comunicativos de la prensa en relación a los niños, se pueden 
identificar ciertos tópicos que tienen sus propias formas de representación.

Los niños observados desde el prisma del problema social, son conceptualizados desde un lugar de víctima de familiares negligentes o maltratadores. La responsabilidad del Estado en relación a estas vulneraciones consiste en la búsqueda y construcción de espacios que cumplan la tarea de distanciar a los pequeños de los riesgos morales y sociales que los circundan. Si bien no se omite flagrantemente el contexto de pobreza, esta se visualiza como un fenómeno sobre el cual se reflexiona de manera aislada: "la pobreza infantil", omitiendo todos los otros actores involucrados en la misma escena.

Así mismo la pobreza no constituye más que un elemento de contexto en el sufrimiento social infantil, la responsabilidad final es de la familia y la solución propuesta no busca reparar los vínculos rotos o la negligencia parental sino construir nuevos artefactos que aborden la tarea de formar.

Los militares, a través de la figura del niño, durante todo el periodo del régimen, dejan traslucir su lado humano, empático y respetuoso de las dinámicas y lenguajes del mundo infantil. Pareciera como si cada acontecimiento relacionado con la crianza o la pedagogía permitiese instruir a la población bajo coordenadas morales. En estos casos los militares son "abuelos" o "padres" y, a su vez, saben lo que es bueno para los chilenos y por ello están habilitados para pronunciarse respecto a las necesidades infantiles.

En ese sentido, los contenidos referidos a la educación son ejemplares para reconstruir el ideal formativo que está a la base de las intervenciones militares en la vida cotidiana de los niños, un ideal humanista y cristiano que se percibe como amenazado por las ideas ideológico-marxistas que contaminan el espíritu de la ciudadanía, pervirtiendo su naturaleza esencialmente bondadosa. La proscripción de libros y contenidos escolares, tiene la finalidad de poner un freno a la difusión de "lecturas" y de ideas.

Por otra parte, la crianza no-ideológica se identifica con las prácticas basadas en la evidencia científica; razón por la cual se acrecienta la presencia en los medios de pediatras y psicólogos, nacionales y extranjeros, prescribiendo mediante insertos en las secciones femeninas las normas de una adecuada mater/paternidad.

Así mismo, la representación de niños y niñas se va transformando permitiendo pesquisar, ya en el año '79, la existencia de un nicho comercial específico y diverso para los niños que consideraría la participación de los mismos para dinamizarse y funcionar.

Hacia fines de los '80 aparecerá una nueva figura de los niños en las noticias del diario La Tercera. En los primeros tiempos de la dictadura los niños y niñas eran víctimas de la pobreza y la negligencia parental, a fines de los '80 aparece más bien como víctimas del terrorismo. Bajo ese prisma se busca fundamentalmente enviar un mensaje al mundo adulto, buscando activamente identificar a quienes con sus acciones ponen nuevamente en peligro la "paz" y la "inocencia".

El recorrido propuesto en esta investigación abre múltiples vías para encaminar investigaciones futuras. Es particularmente interesante el sutil 
trabajo que realizan los medios resituando posicionalmente la población que puede ser tratada según la categoría de infans, ubicando a quienes detentan el poder y por lo mismo, saben lo mejor para Chile como los adultos prescriptores y responsables. Ello reubica una vez más la interrogación respecto a que es lo que define a la niñez ¿una característica cronológica o una situación particular en relación al ejercicio del poder?

\section{Bibliografía}

Alvear, J. 1987. La verdad sobre "El Mercurio": ensayo de crítica periodística. Santiago: Editorial Universitaria.

Bernedo, P., y Porath, W. 2003. "A tres décadas del golpe: ¿Cómo contribuyó la prensa al quiebre de la democracia chilena?" Cuadernos de información (16): 114-124.

Borrelli, M. 2010. “¿Víctimas, héroes o cómplices? Memorias en disputa sobre el rol de la prensa durante la última dictadura militar". AVATARES de la comunicación y la cultura (1): 2-17.

Browne, R. y Del Valle, C. 2010. "Propuesta teóricometodológica para un análisis crítico y complejo del discurso (ACCD) en la prensa en Chile y Perú: El ejemplo de La Cuarta y Ajá". Estudios sobre el mensaje periodístico 17(1): 17-42.

Condeza, R. 2005. "La infancia y la adolescencia en primera plana". Cuadernos de Información de la Pontificia Universidad Católica de Chile (18): 141-147.

Dooner, P. 1989. Periodismo y Política. La prensa de derecha e izquierda 1970-73. Santiago: Editorial Andante.

Dougnac, P. y Lagos, C. 2009. El diario de Agustín: cinco estudios de casos sobre El Mercurio y los derechos humanos (1973-1990) Santiago: Lom Ediciones.

Duarte, C. y Littin, C. 2002. Niñas, Niños y Jóvenes: Construyendo imágenes en la prensa escrita. Santiago: Asociación Chilena Pro Naciones Unidas ACHNU.

Errázuriz, L. 2006. "Política cultural del régimen militar chileno (1973-1976)". Aisthesis: Revista chilena de investigaciones estéticas (40), 62-78.

. 2009. "Dictadura militar en Chile: Antecedentes del golpe estético-cultural". Latin American Research Review 44 (2): 136-157.

Espinoza, V. 2010. "Redes de poder y sociabilidad en la élite política chilena. Los parlamentarios 1990-2005". Polis. Revista dela Universidad Bolivariana 26 (9): 251-286.

Guitelman, P. 2006. La infancia en dictadura: modernidad y conservadurismo en el mundo de Billiken. Buenos Aires: Prometeo.

Herrera, M. 2006. "Operación Colombo: La prensa que se calló con Pinochet". Chasqui. Revista Latinoamericana de Comunicación (96): 18-23.

Jagger, S. 2003. "Discursos y conocimiento: aspectos teóricos y metodológicos de la crítica del discurso y del análisis de dispositivos". Wodaw, R. y Meyer, M. (eds) Métodos de análisis del discurso. España: Gedisa Ediciones.

Marchant, J. P. 2010. "Compañero, Compa', Com: Represión, Lenguaje Y Dictadura Militar". Revista Electrónica de Psicología Política 8 (22): 27-48.

Matta, F. 1986. Investigación sobre la prensa en Chile (19741984) Santiago: CERC.

Molina, L. 2009. "¿Niños o criminales? La representación discursiva sobre los chicos pobres en la prensa gráfica". Actas del IV Coloquio de Investigadores en Estudios del Discurso de la ALED. Buenos Aires. 1-8.

Monckeberg, M. 2009. Los magnates de la prensa. Concentración de los medios de comunicación en Chile. Chile: Penguin Random Huose.

Novaro, M., y Palermo, V. 2003. La dictadura militar, 19761983: del golpe de estado a la restauración democrática. Buenos Aires: Paidos.

Reyes F., Ruiz, C y Sunkel, G. 1986. Investigación sobre la prensa en Chile 1974-1984. Santiago: CERC.

Rojas, J. 2010. Historia de la infancia en el Chile republicano, 1810-2010. Santiago de Chile: Ocho Libros.

Salermo, M. 2006. "Algo Habrán Hecho..." La Construcción De La Categoría" Subversivo" Y Los Procesos De Remodelación De Subjetividades A Través Del Cuerpo Y El Vestido (Argentina, 1976-1983)". Revista de Arqueología Americana: 29-65.

Sepúlveda, R. 2014. "Imaginarios de la niñez criminalizada en América Latina. Los casos de Argentina y Chile". Tesis Doctorado en Estudios Latinoamericanos en la Universidad de Chile, en http://repositorio.uchile.cl/handle/2250/131576 (consultado en 15 de abril de 2016)

Sunkel, O. 1989. "Institucionalismo y estructuralismo". Revista Cepal 38: 147-145.

Valdivia, V. 2010. "¡Estamos en guerra, señores!: el régimen militar de pinochet y el" pueblo", 1973-1980". Historia (Santiago) 43 (1): 163-201.

Valdivia, V. et al. 2006. Su revolución contra nuestra revolución: La pugna marxista-gremalista en los ochenta (2). Santiago: Lom Ediciones.

Vergara, A. 2015. "Los niños como sujetos sociales: El aporte 
de los nuevos estudios sociales de la infancia y el Análisis Crítico del Discurso". Psicoperspectivas de la Pontificia Universidad Católica de Valparaíso, 14 (1): 55-65.

Van Dijk, T. 1990. La noticia como discurso. Comprensión, estructura y producción de la información. Barcelona: Paidós Ediciones.

2000. El discurso como estructura y proceso. Estudios sobre el discurso I. Barcelona: Gedisa. 